\title{
Por una pedagogía de "los inicios".
}

For a pedagogy of "the beginnings"

Charis M. Guiller

https://orcid.org/0000-0002-5078-4726

chguiller@gmail.com

Universidad Nacional de Quilmes | Universidad Nacional de La Plata | Argentina

Por una pedagogía de "los inicios".

Más allá del ingreso a la vida universitaria.

Editoras: Viviana Mancovsky y Stella Maris

Más Rocha.

Editorial Biblos | Saberes y prácticas

2019

\section{RESUMEN}

¿Cuándo un sujeto interesado en seguir una carrera universitaria se vuelve "estudiante"? Así comienza este trabajo de autoría colectiva que se propone indagar acerca de la experiencia de "entrar en la universidad" y transitar el primer año de una carrera universitaria.

PALABRAS CLAVE

Pedagogía,

Universidad,

Primer año

KEY WORDS

Pedagogy,

University,

First year 


\section{PRESENTACIÓN}

El libro aborda la problemática de los inicios de la vida universitaria desde la perspectiva de los sujetos estudiantes y profesores, y sus experiencias en la universidad.

Se trata de una producción colectiva en la que escriben docentes de universidades nacionales argentinas y extranjeras de Brasil, Francia y Colombia.

Las editoras, Viviana Mancovsky y Stella Maris Más Rocha, ambas licenciadas en educación, son docentes e investigadoras de la Universidad de San Martín y de la Universidad Nacional de Lanús, y tienen amplia trayectoria en la educación superior en universidades nacionales.

El trabajo que presentan parte de algunos supuestos relacionados con el inicio de la experiencia de ser estudiante universitario, que surgen de otros trabajos de investigación relevados, tales como: nuevos modos de actuar más autónomos y diferentes a los que se tenían en la escuela secundaria; un proceso de socialización amplio y diverso que lleva a conocer nuevas grupos de pares; un reconocimiento nuevo y diferente por parte de la familia, y una expectativa que se genera a partir de la asistencia a la universidad; $y$ la organización de un tiempo que se comparte con otros para el estudio, la recreación, paseos, participación en actividades culturales, políticas, etc.

La referencia a "los inicios" es elegida porque hace referencia, como señalan las autoras, a un abordaje temporal más amplio en relación a la articulación escuela secundaria-universidad y el ingreso a un nuevo nivel educativo; y porque reconoce experiencias de estudiantes que tienen puntos de partida e historias diferentes y singulares.

En ese sentido, la problemática de "los inicios" se plantea tanto desde el sujeto estudiante como del sujeto profesor en el ámbito universitario.

En las tres partes en que se divide el libro encontramos trabajos de investigación, proyectos institucionales, relatos de experiencias de profesores universitarios, un epílogo y al final un anexo con entrevistas a los autores de algunos de los artículos aquí publicados.

$Y$ se recuperan experiencias de los docentes de cursos de ingreso y primer año que reciben a los estudiantes en las universidades. 


\section{PRIMERA PARTE - INVESTIGACIONES}

En la primera parte el libro da cuenta de investigaciones producto de proyectos de colaboración internacional realizados entre 2015 y 2016 desde las universidades nacionales a las que pertenecen las autoras. En ese sentido, se presentan resultados o avances de investigaciones que estudian a los estudiantes y profesores universitarios.

El primer capítulo de esta primera parte presenta reflexiones en el ámbito de un grupo de investigación llamado Observatorio de Vida Estudiantil (OVE), acompañado por un análisis del contexto de la enseñanza superior en Brasil, a partir de la política de ampliación de oportunidades de acceso a la educación de sectores populares durante las presidencias de Lula da Silva y Dilma Rousseff.

El segundo capítulo indaga la relación con el aprendizaje en un grupo de estudiantes de cinco universidades de París en el contexto francés. Se trata de un estudio sociológico sobre la socialización y la afiliación intelectual de los estudiantes a la universidad, a partir de la exploración centrada en la calidad de sus aprendizajes. El estudio trata de identificar "figuras del aprender" en la universidad y analizar los factores que contribuyen a diferenciar a los estudiantes según el compromiso y la dedicación al estudio.

Y en el tercer capítulo se presentan algunas de las medidas adoptadas en la Universidad Nacional de San Martín (UNSAM) como acciones de inclusión para favorecer la permanencia de los estudiantes en la Universidad. Se explicita de que noción de inclusión en la educación superior se parte, se hace un breve recorrido por la expansión del sistema universitario argentino y las características específicas de la UNSAM. Y se describen algunas políticas institucionales tendientes a la inclusión de los estudiantes para garantizar el derecho a la educación.

\section{SEGUNDA PARTE - PROYECTOS INSTITUCIONALES}

En esta segunda parte se sistematizan cuatro proyectos institucionales de universidades que abordan la problemática de los inicios en la universidad para la inclusión educativa de los estudiantes.

Uno de ellos es la experiencia de la Universidad Nacional Arturo Jauretche (UNAJ), creada en 2009. En este capítulo se realiza una breve historización de su nacimiento. Luego, se desarrolla de manera pormenorizada la perspectiva desde la cual se diseñó el proyecto de la UNAJ a partir de la incorporación de lo que para ellos es un elemento central, la cuestión de los inicios, es decir, la idea de que las experiencias que se construyen en los primeros años de la vida universitaria son fundamentales para las trayectorias de los estudiantes.

Otro de los proyectos presentados es el programa Mentorías entre pares dependiente del área de extensión de la Escuela de Humanidades de la Universidad Nacional de San Martín. El mismo recupera experiencias de apoyo, presencial y virtual entre estudiantes de distintas carreras, a partir de la autogestión estudiantil para luego institucionali- 
zar esas prácticas en el marco de una educación universitaria inclusiva y que sostiene el derecho a la educación superior.

Otro de los proyectos presentados pretende dar a conocer el sistema de educación colombiano, en particular, en el nivel superior, en el marco del Plan Decenal de Educación 2006-2016, reflexionar sobre los esfuerzos del estado para la cobertura, el sistema de ingreso y las estrategias de permanencia para bajar las tasas de deserción estudiantil. Y seguir discutiendo el tema de los inicios y la permanencia a partir del intercambio de experiencias desde la diversidad y la interculturalidad. Y se realizan algunos planteos en torno al papel de la universidad en la formación desde una perceptiva humanística antes que empresarial.

El último capítulo de esta segunda parte, describe la experiencia de creación de un dispositivo de formación destinado a profesores del primer año universitario de la Universidad Nacional de Luján. Se trata de una convocatoria a docentes para que compartan sus saberes construidos a lo largo de sus trayectorias profesionales, que analicen sus estilos de dar clase, analicen el oficio docente, revisen colectivamente sus propias prácticas docentes.

\section{TERCERA PARTE - RELATOS DE EXPERIENCIAS DE PROFESORES UNIVERSITARIOS}

En esta tercera parte se recuperan dos relatos de docentes de la Universidad Nacional de San Martín que abordan diferentes problemáticas vinculadas a la enseñanza en el primer año: un profesor que relata la experiencia de la elección de un texto en el ingreso a la carrera de Filosofía; dos profesoras que relatan los desafíos de las prácticas de lectura y escritura de los estudiantes en el primer año. Asimismo, encontramos el relato de una docente de la Universidad Nacional Arturo Jauretche que cuenta la experiencia de ser docente y dar la bienvenida a los estudiantes ingresantes a la universidad en el Curso de Preparación Universitaria, el Taller de Vida Universitaria y el Ciclo Inicial.

Y el último relato corresponde a una profesora del curso de ingreso de la Universidad Nacional de Lanús que recupera su experiencia docente en los inicios de la vida universitaria de sus estudiantes.

Cierra el libro un Epílogo a cargo de una de las editoras, Viviana Mancovsky que en un esfuerzo por integrar y articular los diversos aportes vertidos en esta producción colectiva propone una pedagogía de los inicios a la vida universitaria, haciendo foco en las dimensiones institucional y relacional, es decir, en el intercambio y encuentro entre los docentes y los estudiantes.

Al final se anexan tres entrevistas realizadas a los tres profesores de Brasil, Francia y Colombia que escriben en el libro.

Sin dudas, un trabajo de consulta obligada para aquellos docentes e investigadores interesados en los inicios de la vida universitaria, y en la articulación escuela secundaria y universidad. 